\title{
Discourse-semantics Analysis of References in two Selected Excerpts from Chimamanda Ngozi Adichie's Americanah
}

\author{
Daniel T. Yokossi ${ }^{1}$ \\ ${ }^{1}$ Assistant Professor, Faculty of Literature, Languages, Arts, and Communications, University of Abomey-Calavi, \\ Republic of Benin \\ Correspondence: Daniel T. Yokossi, Faculty of Literature, Languages, Arts, and Communications, University of \\ Abomey-Calavi, Republic of Benin.
}

Received: September 1, 2020; Accepted: September 21, 2020; Published: September 23, 2020

\begin{abstract}
This article seeks to explore the discourse-semantics of two selected excerpts from Chimamanda Ngozi Adichie's Americanah with a focus on reference chains study. The choice to focus on studying reference chains in the selected excerpts aims at first appraising the way Adichie has used them to realize texture within her studied texts. It second aims at finding the extent to which references have contributed to the encoding of underlying meanings therein. To arrive at this, the research has appealed to the mixed quantitative and qualitative methodology. Through the quantitative methodology, the data obtained after analyses have been summarized organized and presented statistically in an informative way. The qualitative methodology ensued has allowed to give sense to the most interpretable data collected. Indeed, the research has interestingly arrived at impressive results. Among several others, the research has revealed that the studied texts are highly cohesive with endophoric references largely predominating over the other reference types. Using such cohesive ties as Adichie has done, has allowed her texts not only to stick together but also to be highly readable and flow logically. Moreover, the extensive use of endophoric references, as witnessed in the studied texts, is revelatory of their mode which is archetypal of a monologic written text. In other respects, the considerable number of exophoric references in the first excerpt reveals its tenor dimension. Such a linguistic feature indicates that it was produced in a context of immediate faceto-face feedbacks with language accompanying action. On the other hand, the fewer number of the same reference type in the second excerpt reveals its field and unveils that it is a written reflective text reconstructing an experience. Drawing upon the theoretically founded analysis of the selected excerpts and the interpretation of the collected data arrived at, the research opens up to such further investigation areas of the systemic functional linguistics as the interpersonal meaning, the experiential meaning, and the textual meaning.
\end{abstract}

Keywords: discourse-semantics, reference, texture, cohesion

\section{Introduction}

Virtually all the readers of Adichie's Americanah acknowledge that it is an exquisitely written novel. Actually, Americanah is a good read. Whoever reads the novel is not surprised that it won the Chicago Tribune Heartland Prize for fiction. Indeed, the above mentioned novel is a powerful tender story of love, race, home, immigration and identity which keeps no reader unsympathetic. So many people around the globe including myself have read it and admired it. Some among the readership have even rated it five stars. One then wonders what makes it such a good read. To be able to investigate such a concern, I have decided to carry out a discourse-semantics analysis of references in two selected excerpts from the novel.

Exploring such a research theme is significant as it allows to unveil, at the level of the semantics, the field, tenor and mode of the selected texts. Furthermore, it permits, at the discoursal level, to find out the different types of cohesion she has made use of in the selected texts to realize their textures and encode deep meanings. It is further significant because it will unquestionably pave the way for further researches by scholars within the field and serve as a mold for students majoring in linguistics and especially in systemic functional linguistics.

The research aims at first appraising the way reference chains are encoded in the selected texts. It second aims at exploring the extent to which they contribute to the uncovering of deep meanings for a better understanding of the various messages conveyed therein. 
In fact, the research is premised on the hypothesis that Adichie has encoded deep meanings via the field, tenor and mode of the selected excerpts. It is also hypothesized that she has made use of different types of cohesive devices to create texture in her selected texts which makes them exquisite and closely connected pieces.

When we investigate how it is that we, as language users, make sense of what we read in texts, recognize wellconstructed texts as opposed to jumbled or incoherent discourse, and successfully interpret what other language users intend to convey, we are undertaking what is known as discourse analysis (Yule, 2010, p.141).

Language is a tri-stratal semiotic system that involves a stratum of meanings, wordings and of sounds or orthography (Eggins, 1994, p.81). The highest stratum of language viz. the stratum of meanings is also referred to as the discourse-semantics of language (Martin, 1992a) to replace earlier labeling of this stratum (e.g. by Halliday, 1978) by the single term semantics. As a matter of fact, Martin's (1992a) term: discourse-semantics is a doublebarreled one.

From Halliday's $(1978,1985 \mathrm{~b})$ perspective, the semantics part of the above mentioned double-barreled word covers the three aspects in any situation that has linguistic consequences namely field (what the language is being used to talk about), tenor (viz. the role relationships between the interactants and mode (the role language is playing in the interaction). These three aspects also called register variables are respectively associated with: the experiential meaning realized through the transitivity patterns of the grammar, the interpersonal meaning realized through the Mood patterns of the grammar and textual meaning realized through the thematic patterns of the grammar.

As for the discourse part of the discourse- semantic label, it describes the different types of texture that contribute to making texts that is to say, the resources that language has for creating a text ( Halliday \& Hasan, 1976/85). As a matter of fact, texture is what holds the clauses of a text together to give them unity. In fact what belong to the discourse stratum of the systemic model are the systems of all the different text-forming resources of language. Alternatively put, the discoursal part of the discourse semantics describes the types of cohesion through which texture is realized in texts. Indeed, there are four types of cohesion: references, lexical relations, conjunctive relations and conversational structures (Eggins, 1994, pp.95-109). The design of cohesion in text is connected to semantic ties or "relations of meanings that exist within the text, and that define it as a text" (Halliday \& Hassan, 1976).

In addition to the abstract, the introduction and the conclusion that rounds it off, this article goes round such cruxes as theoretical framework, methodology of the research, data analysis and the interpretation of the findings.

\section{Theoretical Framework}

The cohesive resource of reference refers to how the writer/speaker introduces participants and then keeps track of them once they are in the text (Eggins, 1994, p.81). As a matter of fact, participants are the people, places and things that get talked about in the text. The participants in the following sentence taken from the analyzed excerpts available in the appendices are in bold:

"The French school is not bad, but I prefer Sidcot Hall".

Indeed, whenever a participant is mentioned in a text, the writer or speaker must signal to the reader or listener whether the identity of the participant is already known or not. More specifically participants in a text may be either presented to us viz. introduced as "new" to the text or presumed that is to say encoded in such a way that one needs to retrieve their identity from somewhere. In fact, only presuming participants create cohesion in a text, since ties of dependency are constructed between the presuming item and what it refers to i.e. its referent.

The commonest presuming reference items are: the definite article "the", the demonstrative pronouns and adjectives: "this, that, these, those"; the subject and object personal pronouns: "I you, he, she, it, we, they, me, her, him, us, them" and the possessive adjectives and pronouns: "my, your, his, her, its, our, their, mine, yours, hers, ours, theirs."

It is highly important for readers or listeners to retrieve the identity of a presuming reference item used by writers or speakers in order for them to be able to follow their texts. Actually, if presuming referents are not retrievable, the interaction will run into problems. For example, note the ambiguity of the pronoun she in this fragment:

My wife and my mother were at home and my daughter was with me in my office. She couldn't figure out what happened later on.

Indeed, presuming reference items identities may be retrievable from a number of different contexts. As a matter of fact, they may be retrieved from the general context of culture. For instance, when one talks about how great 
the Almighty God is one knows which God s/he is talking about: the Almighty God people share as believers in this world. Retrievals from the shared context of culture are called homophoric references.

In other respects, presuming reference items can also be retrieved from the immediate context of situation. For example, if I tell you this:

\section{Open it and hand it over to her}

If we are in the same place at the same time you will be able to decode that "it" refers to whatever object I hold in hands or that I'm pointing to, and "her" refers to the female around. When one retrieves from a shared immediate situational context, this is called exophoric reference.

The identity of a presuming reference item can also be retrieved from within the text, in which case we are dealing with endophoric reference. It is endophoric references which create cohesion, since endophoric ties creates the internal texture of the text, while homophoric and exophoric references contribute to the text (situational) coherence. To descend to particulars, endophoric references can be of five main kinds namely anaphoric, cataphoric, esphoric, comparative and bridging.

An endophoric reference is said to be anaphoric when the referent has appeared at an earlier point in the text as He in the following example referring back to the participant Peter: Peter is a well-mannered gentleman. He is hardworking as well.

Typically, an anaphoric reference refers to a participant mentioned nearby (one or two sentences previously), but sometimes it may refer back to an item mentioned many pages/minutes or even hours ago.

Endophoric reference items can also be cataphoric particularly when the referent has not yet appeared, but will be provided subsequently. An illustrative example is the following:

The point is this: I didn't know that the onus was on me to call the boss Here, the demonstrative pronoun "this" indicates a presumed referent, but one only discovers what is referred to in the immediately following clause.

When the referent occurs in the phrase immediately following the presuming referent item that is to say within the same nominal group or noun phrase, not in a separate clause, the endophoric reference is said to be esphoric. The following is an illustrative example:

We ran into each other at the market place where they sell vegetables.

The definite article "the" tells us that we know which market place (it is a presuming reference item), but rather than looking back to an earlier part of the text to discover which market place, we are immediately told which one in the following part of the nominal group where they sell vegetables.

One further type of endophoric reference which can operate anaphorically, cataphorically or esphorically is the comparative reference. With comparative references, the identity of the presumed item is retrieved not because it has already been mentioned or will be mentioned in the text, but because an item with which it is being compared has been mentioned. For example, one could follow the statement Rina is poor, with sentences such as the following, each of which involves the comparative tie (the comparative reference item has been underlined):

Her other problems include joblessness and loneliness.

Such problems can lead to self- hatred and despair.

A different but equally common problem is that she trusts nobody.

Something else that is happening to her is that she fails in whatever she undertakes.

One more special kind of reference is known as bridging reference. This is when a presuming reference item refers back to an early item from which it can be inferentially derived as in the following example:

\section{All these problems can lead a lady of her age to commit suicide.}

Indeed, the reference item "these" signals that one knows which problems are being referred to. In fact, no previous mention of a lady of a certain age having so many problems to the point of committing suicide has been made, but one can "bridge" from Rina's problems mentioned earlier above to interpret who is being talked about.

Although reference items typically refer to a specific participant, in whole text referencing the referent may be "the text up to this point", or a sequence of actions or events mentioned previously.

A different type of reference known as locational reference, is one which involves not the identification of a participant in a text (a person or thing), but the identification of a location in time or space. As a matter of fact, locational referents to nearby time or space such as here, now, these days, at the moment, above, below are 
frequently retrieved exophorically, while such locational items referring to distant time/space as there, then are often endophorically retrieved.

\section{Methodology}

To be able to attain the purpose of this research scientifically, two excerpts that fit to the study carried out in this article have been culled from Adichie's Americanah. In addition to that criterion of suitability to the study, both excerpts have been selected because they follow each other logically in the unfolding of the story narrated therein. More specifically, the second excerpt is the logical result of the first one. Besides, the research design appealed to in this article is that of the mixed quantitative and qualitative methodology. Following the quantitative methodology that has paved the way to the qualitative methodology, a theoretically founded reference analysis of the selected excerpts has been carried out following the discourse-semantics principle of texts description. Indeed, the units of analysis have been the selected texts. More to that point, the analysis has been carried out following the keys designed for the identification of the various references embedded in the chosen texts. In fact the description keys are presented in the appendices right before the analyses proper. Once the data have been collected, they have been summarized, organized, numerated, categorized and tabulated statistically. The qualitative methodology ensued has allowed to dig out, via the interpretation of the most interpretable recorded linguistic patterns of the excerpts, the encoded meanings of the collected data for a deeper understanding of the selected texts.

\section{Data Analysis}

The analysis has been carried out following the analysis keys presented right at the beginning of the appendices made available at the bottom of the present article. The findings of the analysis in terms of the number of references identified in the selected excerpts have been summarized, organized, numerated, categorized and tabulated statistically below for a better visibility of the recorded miscellaneous references embedded in the studied excerpts as well as their values in percentage per excerpt.

Table 1. Statistical table of the various types of references identified in the selected excerpts

\begin{tabular}{|c|c|c|c|}
\hline \multirow{2}{*}{\multicolumn{2}{|c|}{ Types of Reference }} & Excerpt $\mathrm{N}^{\circ} 1:$ & Excerpt $\mathrm{N}^{\circ} 2$ \\
\hline & & Number \& Percentage & Number \& Percentage \\
\hline \multicolumn{2}{|l|}{ Homophoric reference } & $32(5.71 \%)$ & $17(3.71 \%)$ \\
\hline \multicolumn{2}{|l|}{ Exophoric reference } & $33(5.89 \%)$ & $11(2.40 \%)$ \\
\hline \multirow{5}{*}{ Endophoric references } & Anaphoric reference & $420(75 \%)$ & $388(69.28 \%)$ \\
\hline & Cataphoric reference & $25(4.46 \%)$ & $09(1.96 \%)$ \\
\hline & Esphoric reference & $01(0.17 \%)$ & $01(0.21 \%)$ \\
\hline & Comparative reference & $06(1.07 \%)$ & $03(0.65 \%)$ \\
\hline & Bridging reference & $01(0.17 \%)$ & $04(0.87 \%)$ \\
\hline \multirow{2}{*}{ Locational reference } & to nearby time or space & $38(6.78 \%)$ & $22(4.80 \%)$ \\
\hline & to distant time or space & $04(0.71 \%)$ & $03(0.65 \%)$ \\
\hline \multicolumn{2}{|c|}{ Total number of references per excerpt } & $560(100 \%)$ & $458(100 \%)$ \\
\hline \multicolumn{2}{|c|}{ Overall number of references in both selected excerpts } & \multicolumn{2}{|c|}{1,018} \\
\hline
\end{tabular}

Examining the statistical table above, one can notice that both selected excerpts have been conducive to the research work at hand as they embed all the different types of references presented in the theoretical section of this article though at a relatively different proportions. As a matter of fact, the first excerpt records a higher number of reference types (560) than the second excerpt that counts fewer (458) different kinds of references. In fact, the recorded summative number of references in both excerpts adds up to one thousand eighteen $(1,018)$. To descend to particulars, endophoric references come top in both studied excerpts with an aggregate number of 453 representing $80.89 \%$ of the overall references recorded in the first excerpt. The cumulative number of 405 on the other hand, represents $88.42 \%$ of the references recorded in the second excerpt. It is of utmost importance to remark, at this level, that the anaphoric references, a sub-category of the endophoric references class, outstandingly prevail over the other sub-categories with a crushing number of 420 in the first excerpt. They represent $75 \%$ of all the different types of references identified in the excerpt. In the second excerpt, they recorded 388 that is, $69.28 \%$ of the recorded miscellaneous references. Conversely, the esphoric references are at the bottom of the endophoric references class and count exactly the same number (01) in both studied excerpts representing, as a result, $0.17 \%$ of the recorded references in the first excerpt and $0.21 \%$ in the second excerpt. A look at the statistical table tells 
more about the endophoric references class and the proportions of its various sub-categories in terms of number and percentage in both studied excerpts.

The endophoric references are followed in the ranking order by the locational references which are a total of 42 $(7.5 \%)$ and $25(5.45 \%)$ in the first and the second excerpts respectively. Whether in the first or the second excerpt, the locational references to nearby time or space dominate over those to distant time or space. More specifically, while the locational references to nearby time or space are 38 viz. $6.78 \%$ of the overall reference types embedded in the first excerpt, the locational references to distant time are just 4 in number representing just $0.71 \%$ of the recorded references in that same excerpt. Likewise, in the second studied excerpt, locational references to nearby time or space get the upper hand over the locational references to distant time or space. while the former ones count a total number of $22 \mathrm{viz} .4 .80 \%$ of the whole recorded references in the excerpt, the latter ones, on the other hand, are just 03 in number i.e. $0.65 \%$ of the identified references in the except.

Homophoric references come third in rank in both studied excerpts with a total number of $32(5.71 \%)$ and 17 $(3.71 \%)$ in the first and second excerpts respectively. Exophoric references are at the bottom in the analyzed excerpts and are 33 in the first excerpt representing $5.89 \%$ of the total number of references embedded in the excerpt. The second excerpt records a largely fewer number of 11 exophoric references i.e. $2.40 \%$ of all the different types of references recorded in it.

The statistical analysis of the data carried out above has helped to find out the statistical features of the studied excerpts. As for their implied meanings, they are going to be discussed in the following section.

\section{Interpretation of the Findings}

One important thing is to be able to carry out linguistic descriptions drawing upon linguistic theories. But another more important thing is to be able to provide the requisite interpretation of the linguistic patterns recorded after describing them based on theoretical perspectives. Thus, this section, as its title suggests, focalizes on the interpretation of the linguistic features displayed in the foregoing part of this article. Indeed, this part of the article is one via which essence is going to be given to the selected excerpts linguistic patterns as it is going to be devoted to the digging out of the hidden messages behind them.

The reference patterns of the studied excerpts have revealed, in the light of the above statistical table, their key participants/ characters. As a matter of fact, both excerpts are fundamentally concerned with Obinze, his wife Kosi and his former girl friend Ifemelu living abroad far away from him, still unmarried after her very last break up with a black American. In fact, the reference chains that span both studied excerpts are the ones that are related to the above mentioned participants. The self-reference and anaphoric as well as cataphoric chains that relate to the latter ones are preponderantly denser i.e. having the greater number of references than the other reference chains recorded in the studied excerpt. Through the events of both selected excerpts, which in fact go round Obinze's couple, Adichie has insightfully depicted how mismanaged old friendships especially with ex-girlfriends can negatively impact men's currently established households' harmony and happiness. Though Obinze's family is introduced to the reader as a peacefully happy one his couple is not that happy as his behavior and mindset towards his ex-girlfriend Ifemelu whom he still seems to be in love with loom a bad omen for his present family. On several occasions Obinze has been absent minded when he is with his wife Kosi just because Ifemelu his ex-girlfriend is almost always present in his mind despite Kosi's various efforts to cherish him. For example in the sixth paragraph of the second excerpt on page 427 Kosi said this "Your mind is not here". The possessive adjective "Your" in the quotation above is an anaphoric item referring back to Obinze. Truly Obinze's mind was really not with Kosi. He was fully snowed under with ideas about his ex-girlfriend though he is right now supposed to be concerned with finding out which School his little daughter Butchi would attend. Earlier on the penultimate paragraph on page 425 Kosi told Obinze the following: "Darling you're not paying attention" when he laughed at his own absurdity that he wanted to buy a ticket, get on a plane to America and be with Ifemelu to console her because in her very last e-mail she sent him as a reply to his own message to her, she told him that Dike attempted suicide and that it had been traumatic to her and had affected her. Poor lady Kosi! She thought her husband was laughing about something that had to do with his work. She could not imagine that her husband was enjoying a communication exchange he had had earlier with his ex, her possible future rival. Indeed, portraying Obinze this way as an irresponsible husband with a restless and wandering mind, highly prone to unfaithfulness, that has almost all his heart for his ex-girlfriend not for his current wife even less for his little daughter, and at the same time Kosi his actual wife undergoing such moral torture as a very hospital, peaceful, trustworthy, and well-meaning devoted woman, is Adichie's feministic trend to take revenge on some men's inconsistency, proven debauchery and second to none irresponsibility. 
In other respects, there is no consistency in the participants developed in both studied excerpts. Whether in the first or the second excerpt, a large number of such participants as: Mrs Akin-Cole, Mrs. Adamma, Chief, Ferdinand, Yemi, Ranyinudo, Butchi, Dele, Gabriel, Okwudiba, Marie, the Black American, Obinze's mother, Dike, Isioma and the headmistress, get introduced to the reader in addition to the main ones named above. However, they have been important for short portions of the explored texts after their introductions giving way to the narration of the key events about Obinze's household and his extra-marital friendship with his ex-girlfriend Ifemelu. These changes in participants as Obinze's story unfolds correspond to Adichie's narration of the different plots involved in that story. In the same vein, Adichie's choices of the participants that first got introduced to the readers as new and later on as presumed ones at specific points in the unfolding of her texts account for the latter ones discourse domain. Furthermore, such quick switches from and back to the main story being narrated has certainly been a narrative technique. Such a technique has been used by Adichie to break up with monotony in the narration process of her long story and to create suspense from time to time in the writing process. This technique helps keep her readers connected without boredom. This way of organizing the messages of the studied excerpts has both revealed and largely contributed to their textual semantics.

It is of utmost importance to underscore that the studied texts are highly cohesive with the endophoric references largely predominating over the other reference types. While the first excerpt records 453 endophoric references all sub-categories included representing $80.89 \%$ of the total number of $560(100 \%)$ various references recorded in that excerpt, the second excerpt, on the other hand, counts 405 endophoric references which represents $88.42 \%$ of the $458(100 \%)$ different references recorded in the excerpt. Such preponderant use of endophoric references is revelatory of Adichie's writing style. Actually, in the studied excerpts, she has used excessive cohesive ties making it very easy for her readers to connect pieces of information as the different plots of the story she writes about unfold on the one hand, and to ensure that her readers guess what the main ideas of her writings are on the other hand. Using so many cohesive ties as she has done, has allowed her texts not only to stick together but also to be highly readable and flow logically. Moreover, the extensive use of endophoric references, as witnessed in the studied texts, is revelatory of their mode which is, in fact, typical of a monologic written text.

Examining the statistical pieces of information reveals that the first excerpt counts 33 (5.89\%) exophoric references whereas the second excerpt contains just 11 of the same reference type. Indeed these exophoric ties in both texts reflect the interactive, face-to-face context in which the story is narrated and thereby account for the mode in which the text was constructed. As a matter of fact, the remarkable unbalance of the number of exophoric references in both selected extracts from the same novel though from different page ranges can then be explained by the simple fact that the first excerpt is more dialogically written than the second one. To be more specific, the considerable number of exophoric references in the first excerpt, as can be witnessed from the above statistical analysis, is indicative that the first studied text was produced in a context of immediate face-to-face feedbacks with language accompanying action which highlights the tenor dimension of the excerpt. On the other hand, the fewer number of the same reference type in the second excerpt, which however has a highly extensive reliance on endophoric references, unveils its field and indicates that it is a written reflective text reconstructing an experience. More to that point, as exophoric references are retrievals from the immediate context of situation, their presence at that rate in both selected excerpts in addition to the retrievals from the shared context of culture viz. the homophoric references which are also not trifling at all in both studied texts is indicative of the fact that the studied excerpts are to a large extent context-dependent for their sound understanding. For example the exophoric reference "we" in Obinze's following statement: "Didn't we all go to primary schools that taught the Nigerian curriculum" gets its full meaning only when put in its immediate situational context. As a matter of fact Obinze, in the above statement, has used the exophoric reference "we" to refer to himself, Mrs. Akin-Cole, Mrs. Adamma and his wife Kosi who were discussing about the right school to send the little daugter Butchi to. Looking more deeply into that immediate situational context of the exophoric reference pinpointed above, one understands that beyond the personae of the excerpt it really refers immediately to, it is also used to refer to all the native Nigerians who have grown up in their country and have attended the same local schools being rejected today for reasons that seem not convincing for him at all. Obinze's question implies that the Nigerian curriculum is not bad in itself because that was the curriculum they were all taught and have however all succeeded in life. So why should Mrs. Akin-Cole and Adamma, just like several other Africans think that the French and the British curricula are the best and are the only recommendable ones that would ensure the wholeness of their children? Obinze may be right to view things the way he does but what he has forgotten that the female writer Adichie is implicitly calling attention to, is that the time which he is referring back to which fuels his stand is really a bygone age that actually has nothing to do with the present time in the twenty first century where things have largely evolved and have beaten the realities of the past. Just like Obinze, many Africans in general and African leaders in particular are still inclined to the past to the point of losing sight of the present and the future which, however, matter much more for the development 
of their countries and, by extension, of their continent. Such is certainly the message being conveyed here by Adichie to her readership.

In other respects, drawing upon the depiction of the events as presented above, Adichie is, without doubt, calling Africans' attention to the fact that Africa would never get developed if Africans should remain dependent on foreign customs, culture, traditions and technologies. Indeed no nation worldwide can get to their full development without putting their civilization before other nations' one. How can Africans get developed if they have no solid educational systems? Africans should join hands and get up like one person in perfect unity to establish successful educational systems with modern challenging curricula and high technologies where teachers and lecturers are very well trained for their jobs for the development of their dear continent. It is true that with the current financial crises which can possibly result into social crises in the long run if care is not taken, caused by the covid-19 pandemic, and all the good lessons learnt from it nowadays on the one hand, added to the worldwide globalization process still in progress thereby all continents of the world are bound to collaboration on the other, Africans won't be able to wave aside other nations but they should not as well depend on them for their basic needs.

The data obtained after analysis has revealed that the locational references of both types have been recorded in both studied excerpts. A striking common linguistic feature to both excerpts is that the locational references to nearby time or space largely outnumber those to distant time or space. Such distribution of these linguistic patterns indicates that Adichie, in the studied excerpts, has written about topical social issues that deserve careful attention, concrete and beneficial actions to get Africans, their families as well as their continent, by and large, out of the rut for better and brighter living conditions and a sustainable development. Conversely, the locational references to distant time or space, as used in the studied excerpts, are a foray into the past to learn from it for serious actions to be taken in the present to foster a brighter future.

\section{Conclusion}

This article has explored the cohesive resource of reference in two excerpts culled from Adichie's novel entitled Americanah to scrutinize how she has both encoded and kept track of her different participants in the studied texts to allow her readers to follow her and decode her full messages constructed around them as the plots they are involved in get unfolds. The paper has appealed to the mixed quantitative and qualitative research methodology. Via the quantitative method, statistics of the data collected from both studied excerpts after analyses, have been summarized, organized and presented in an informative way in a recap statistical table for the overall display of the excerpts linguistic patterns with a view to the interpretation that ensued following the qualitative method. The article has, at the level of the interpretation of the findings, arrived at very impressive results. Among several other findings available under the interpretation of the findings section, the study has allowed to validate the hypothesis that Adichie, in the studied excerpts, has made use of different types of cohesive devices to create texture in her selected texts which makes them exquisite and closely connected pieces. Such a writing technique has made it very easy for her readers to connect pieces of information as the different plots of the story she writes about unfold. It further ensures that her readers guess what the key encoded messages of her writings are, which confirms the second hypothesis that Adichie has encoded deep meanings via the field, tenor and mode of the selected excerpts. More to the point, using so many cohesive ties as she has done, has allowed her texts not only to stick together but also to be highly readable and flow logically. Furthermore, the study has also unveiled, via the anaphoric patterns of both studied excerpts how mismanaged old friendships especially with ex-girlfriends can negatively impact men's currently established households' harmony and happiness. In addition, the study has also revealed that the changes in participants as Obinze's story unfolds correspond to Adichie's narration of the different plots involved in that story. Furthermore, the extensive number of exophoric references in the first excerpt is indicative that it was produced in a context of immediate face-to-face feedbacks with language accompanying action which sheds light on its tenor dimension. On the other hand, the fewer number of the same reference type in the second excerpt, which however has a highly extensive reliance on endophoric references, unveils its field indicating that it is a written reflective text reconstructing, as a result, an experience.

The research has interestingly opened up to such further investigation areas of the systemic functional linguistics as the interpersonal meaning, the experiential meaning, and the textual meaning, for as systemicists claim it, any text is the realization of not just one meaning but three main kinds of meanings at one time (Eggins, 1994, p.82).

\section{References}

Adichie, N. C. (2013). Americanah. Nigeria: Farafina.

Eggins, S. (1994). An Introduction to Systemic Functional Linguistics. London, UnitedKingdom: Printer publishers Ltd. 
Gee, J. P. (2006). An introduction to Discourse analysis: Theory and method, 2nd editionNew York: Routledge

Gillian, B., \& Yule, G. (1989). Discourse Analysis. Cambridge: Cambridge University Press.

Halliday, M. A. K. (1978). Language as social semiotic. London: Edward Arnold.

Halliday, M. A. K. (1985 a). Introduction to Functional Grammar. London: Edward Arnold.

Halliday, M. A. K. (1985b). Spoken and Written Language. Greelong, Vic: Deakin UniversityPress.

Halliday, M. A. K. (1994). Introduction to Functional Grammar London, New York, etc: Arnold.

Halliday, M. A. K., \& Hasan, R. (1976). Cohesion in English. London: Longman.

Halliday, M. A. K., \& Martin, J. R. (1993). Writing Science. Literary and Discursive Power. London: The Falmer Press.

Halliday, M. A. K., \& Hasan, R. (1985). Language, Text and Context. Vic: DeakinUniversity Press.

Hoey, M. (2001). Textual Interaction: An Introduction to Written Discourse Analysis; Oxford: Routledge.

Martin, J. R. (1992a). English Text: system and structure. Amsterdam: Benjamins.Nunan, David. (1993) Introducing Discourse Analysis. New York: Penguin English.

Titscher, Stefan, et al. (2000) Method of Text and Discourse Analysis. London: SAGE Publications.

Yule, G. (2010). The Study of Language ( $4^{\text {th }}$ ed.). USA: Cambridge University Press.

\section{Appendices}

The analyses below have been carried out following the discourse-semantics principle of describing texts. As a matter of fact, knowing that the unit of analysis admitted for the discourse-semantics stratum of language by scholars within the framework of systemic Functional Linguistics is text, the keys hereafter have been designed for the description to help highlight distinctively the different types of reference embedded in the selected texts: $\mathbf{H}$ : Homophoric reference; $\mathbf{X}$ : exophoric reference; $\mathbf{A}$ : anaphoric reference; $\mathbf{C}$ : cataphoric reference; $\mathbf{S}$ : esphoric reference; $\mathbf{P}$ : comparative reference; $\mathbf{B}$ : Bridging reference; $\mathbf{L}$ : locational reference.

\section{Excerpt $\mathrm{N}^{\circ} \mathbf{1}$}

As soon as they $(\mathbf{C})$ arrived at Chief's party, Kosi led the way around the room, hugging men and women she (A) barely knew, calling the older ones "ma" and "sir" with exaggerated respect, basking in the attention her (A) face drew but flattening her(A) personality so that her (A) beauty did not threaten. She (A) praised a woman's hair, another's dress, a man's tie. She (A) said "We (X) thank God" often. When one woman asked her (A), in an accusing tone, "What cream do you (A) use on your (A) face? How can one person have this kind of perfect skin?"Kosi laughed graciously and promised to send the woman a text message with details of her (A) skin-care routine.

Obinze had always been struck by how important it(C) was to her (A) to be a wholesomely agreeable person, to have no sharp angles sticking out. On Sundays, she (A) would invite his (A) relatives for pounded yam and onugbu soup and then watch over to make sure everyone was suitably overfed. Uncle, you (A) must eat o! There is more meat in the kitchen! Let me (A) bring you (A) another Guinness! The first time he (A) took her (A) to his (A) mother's house in Nsukka, just before they (A) got married, she (A) leaped up to help with serving the food, and when his (A) mother made to clean up afterwards, she (A) got up, offended, and said, "Mummy, how can I (A) be here and you (A) will be cleaning?" She (A) ended every sentence she (A) spoke to his (A) uncles with "sir." She (A) put ribbons in the hair of his (A) cousins' daughters. There was something immodest about her modesty: it (A) announced itself.

Now she(A) was curtseying and greeting Mrs. Akin-Cole, a famously old woman from a famously old family, who had the supercilious expression, eyebrows always raised, of a person used to receiving homage; Obinze often imagined her(A) belching champagne bubbles.

"How is your (A) child? Has she (A) started school?" Mrs. Akin-Cole asked. "You (A) must send her (A) to the French school. They (A) are very good, very rigorous. Of course they (A) teach in French but it(C) can only be good for the child to learn another civilized language, since she (A) already learns English at home."

“Okay, ma. I(C)'ll look at the French school," Kosi said.

"The French school is not bad, but I(C) prefer Sidcot Hall. They (A) teach the complete British curriculum," said another woman, whose name Obinze had forgotten. He (A) knew she (A) had made a lot of money during General 
Abacha's government. She (A) had been a pimp, as the story went, providing young girls for the army officers who, in turn, gave her $(\mathbf{A})$ inflated supply contracts. $\operatorname{Now}(\mathbf{L})$, in her(A) tight sequinned dress that (A) outlined the swell of her(A) lower belly, she(A) had become a certain kind of middle-aged Lagos woman, dried up by disappointments, blighted by bitterness, the sprinkle of pimples on her(A) forehead smothered in heavy foundation.

“Oh, yes, Sidcot Hall," Kosi said. "It (A)'s already on top of my (A) list because I (A) know they (A) teach the British curriculum."

Obinze would ordinarily not have said anything at all, just watched and listened, but today (L), for some reason, he (A) said, "Didn't we(X) all go to primary schools that (A) taught the Nigerian curriculum?"

The women looked at him (A); their (A) puzzled expressions implied that he (A) could not possibly be serious. And in some ways, he (A) was not. Of course he (A), too, wanted the best for his (A) daughter. Sometimes, like now (L), he (A) felt like an intruder in his (A) new circle, of people who believed that the latest schools, the latest curriculums, would ensure the wholeness of their (A) children. He (A) did not share their (A) certainties. He (A) spent too much time mourning what could have been and questioning what should be.

When he (A) was younger, he (A) had admired people with moneyed childhoods and foreign accents, but he (A) had come to sense an unvoiced yearning in them (A), a sad search for something they (A) could never find. $\mathrm{He}(\mathbf{A})$ did not want a well-educated child enmeshed in insecurities. Buchi would not go to the French school, of that he (A) was sure.

"If you(X) decide to disadvantage your (A) child by sending her (A) to one of these schools (A) with half-baked Nigerian teachers, then $(\mathbf{L})$ you(X) only have yourself to blame," Mrs. Akin-Cole said. She(A) spoke with the unplaceable foreign accent, British and American and something else(P) all at once, of the wealthy Nigerian who did not want the world to forget how worldly she(A) was, how her(A) British Airways executive card was choking with miles.

"One of my(C) friends, her(A) son goes to a school on the mainland(L) and do you(X) know, they(A)have only five computers in the whole school(L). Only five!" the other woman said. Obinze remembered her (A) name now (L). Adamma.

Mrs. Akin-Cole said, "Things have changed."

"I(C) agree," Kosi said. "But I (A) also see what Obinze is saying."

She (A) was taking two sides at once, to please everyone; she (A) always chose peace over truth, was always eager to conform. Watching her(A) now(L) as she(A) talked to Mrs. Akin-Cole, the gold shadow on her(A) eyelids shimmering, he(A) felt guilty about his(A) thoughts. She (A) was such a devoted woman, such a well-meaning, devoted woman. He (A) reached out and held her (A) hand.

"We (A)'ll go to Sidcot Hall and the French school, and also look at some Nigerian schools like Crown Day," Kosi said, and looked at him (A) with a plea.

"Yes," he (A) said, squeezing her (A) hand. She (A) would know it (A) was an apology, and later, he (A) would apologize properly. He (A) should have kept quiet, left her (A) conversation unruffled. She (A) often told him (A) that her (A) friends envied her (A), and said he (A) behaved like a foreign husband, the way he (A) made her (A) breakfast on weekends and stayed home every night. And, in the pride in her (A) eyes, he (A) saw a shinier, better version of himself. He(A) was about to say something to Mrs. Akin-Cole, something meaningless and mollifying, when he(A)heard Chief's raised voice behind $\operatorname{him}(\mathbf{A})$ : "But you(X) know that as we(X) speak, oil is flowing through illegal pipes and they(X) sell it(A) in bottles in Cotonou(L)! Yes! Yes!"

Chief was upon them (A).

"My(C) beautiful princess!" Chief said to Kosi, and hugged her (A), pressing her (A) close; Obinze wondered if Chief had ever propositioned her (A). It (A) would not surprise him (A). He(A) had once been at Chief's house when a man brought his(A) girlfriend to visit, and when she(A) left the room to go to the toilet, Obinze heard Chief tell the man, "I(A) like that(A) girl. Give her (A) to me and I (A) will give you (A) a nice plot of land in Ikeja (L)."

"You(C) look so well, Chief," Kosi said. "Ever young!"

"Ah, my $(\mathbf{C})$ dear, $\mathrm{I}(\mathbf{C})$ try, $\mathrm{I}(\mathbf{C})$ try." Chief jokingly tugged at the satin lapels of his $(\mathbf{A})$ black jacket. He (A) did look well, spare and upright, unlike many of his (A) peers who looked like (P) pregnant men.

"My(C) boy!" he (A) said to Obinze.

"Good evening, Chief." Obinze shook his (A) hand with both hands, bowing slightly. He (A) watched the other men at the party bow, too, clustering around Chief, jostling to out laugh one another when Chief made a joke. 
The party was more crowded. Obinze looked up and saw Ferdinand, a stocky acquaintance of Chief's who had run for governor in the last elections, had lost, and, as all losing politicians did, had gone to court to challenge the results. Ferdinand had a steely, amoral face; if one examined his (A) hands, the blood of his (A) enemies might be found crusted under his (A) fingernails. Ferdinand's eyes met his (A) and Obinze looked away. He (A) was worried that Ferdinand would come over to talk about the shady land deal he(A)had mentioned the last time they(A) ran into each other, and so he(A) mumbled that he(A) was going to the toilet and slipped away from the group.

At the buffet table, he (A) saw a young man looking with sad disappointment at the cold cuts and pastas. Obinze was drawn to his (A) gaucheness; in the young man's clothes, and in the way that he (A) stood, was an outsiderness he (A) could not shield even if he (A) had wanted to.

"There's another table on the other side with Nigerian food," Obinze told him (A), and the young man looked at him (A) and laughed in gratitude. His (A) name was Yemi and he (A) was a newspaper journalist. Not surprising; pictures from Chief's parties were always splattered in the weekend papers.

Yemi had studied English at university and Obinze asked him(A) what books he(A) liked, keen to talk about something interesting at last, but he(A)soon realized that, for Yemi, a book did not qualify as literature unless it(A) had polysyllabic words and incomprehensible passages.

"The problem is that $(\mathbf{A})$ the novel is too simple, the man does not even use any big words," Yemi said.

It(C) saddened Obinze that Yemi was so poorly educated and did not know that he (A) was poorly educated. It (A) made him (A) want to be a teacher. He (A) imagined himself (A) standing in front of a class full of Yemis, teaching. It (A) would suit him (A), the teaching life, as it (A) had suited his (A) mother. He (A) often imagined other things he (A) could have done, or that he (A) could still do: teach in a university, edit a newspaper, coach professional table tennis.

"I(C) don't know what your(C) line of business is, sir, but $\mathrm{I}(\mathbf{C})$ am always looking for a better job. I'(C)m completing my(C) master's now $(\mathbf{L})$," Yemi said, in the manner of the true Lagosian who was always hustling, eyes eternally alert to the brighter and the better; Obinze gave him(A) his(A) card before going back to find Kosi.

"I(C) was wondering where you (A) were," she (A) said.

"Sorry, I(C) ran into somebody," Obinze said. He (A) reached into his (A) pocket to touch his (A) BlackBerry. Kosi was asking if he (A) wanted more food. He (A) didn't. He (A) wanted to go home. A rash eagerness had overcome him (A), to go into his (A) study and reply to Ifemelu's e-mail, something he (A) had unconsciously been composing in his (A) mind. If she (A) was considering coming back to Nigeria, then it (A) meant she (A) was no longer with the black American. But she(A) might be bringing him(A) with her(A); she(A) was after all the kind of woman who would make a man easily uproot his(A) life, the kind who, because she(A) did not expect or ask for certainty, made a certain kind of sureness become possible. When she (A) held his (A) hand during their (A) campus days, she (A) would squeeze until both palms became slick with sweat, and she (A) would say, teasing, "Just in case this (A) is the last time we (A) hold hands, let's (A) really hold hands. Because a motorcycle or a car can kill us(A) now(L), or I(A) might see the real man of my(A) dreams down the street and leave you(A) or you(A) might see the real woman of your(A)dreams and leave me(A)." Perhaps the black American would come back to Nigeria, too, clinging on to her (A). Still, he (A) sensed, from the e-mail, that she (A) was single. He (A) brought out his (A) BlackBerry to calculate the American time when it (A) had been sent. Early afternoon. Her (A) sentences had a hasty quality; he (A) wondered what she (A) had been doing then (L). And he (A) wondered what else (P) Ranyinudo had told her (A) about him (A).

On the Saturday in December when he (A) ran into Ranyinudo at the Palms mall, he (A) was carrying Buchi in one arm, waiting at the entrance for Gabriel to bring the car around, and holding a bag with Buchi's biscuits in the other hand. "The Zed!'Ranyinudo called out. In secondary school she (A) had been the bubbly tomboy, very tall and skinny and straightforward, not armed with the mysteriousness of girls. The boys had all liked her(A)but never chased her(A), and they(A) fondly called her(A) Leave $\operatorname{Me}(\mathbf{X})$ in Peace, because of how often she(A) would say, whenever asked about her(A) unusual name, "Yes, it(A) is an Igbo name and it(A) means 'leave us(X) in peace,' so you(X) leave me(A) in peace!" He (A) was surprised at how chic she (A) looked now (L), and how different, with her (A) short spiky hair and tight jeans, her (A) body full and curvy.

"The Zed-The Zed! Longest time! You (A) don't ask about us(X) again. Is this(C) your daughter? Oh, bless! The other day I (A) was with one my (A) friends, Dele. You (A) know Dele from Hale Bank? He (A) said you (A) own that building near the Ace office in Banana Island? Congratulations. You (A)'ve really done well o. And Dele said you (A) are so humble." 
He (A) had been uncomfortable, with her (A) overdone fussing, the deference that (A) seeped subtly from her (A) pores. $\mathrm{He}(\mathbf{A})$ was, in her(A) eyes, no longer The Zed from secondary school, and the stories of his(A) wealth made her(A) assume he(A) had changed more than he(A) possibly could have. People often told him(A) how humble he(A)was, but they(A) did not mean real humility, it(A) was merely that he(A) did not flaunt his(A) membership in the wealthy club, did not exercise the rights it(A) brought - to be rude, to be inconsiderate, to be greeted rather than to greet-and because so many others like him(A) exercised those(A) rights, his(A) choices were interpreted as humility. He (A) did not boast, either, or speak about the things he (A) owned, which (A) made people assume he (A) owned much more than he (A) did. Even his (A) closest friend, Okwudiba, often told him (A) how humble he (A) was, and it (A) irked him (A) slightly, because he(A) wished Okwudiba would see that to call him(A) humble was to make rudeness normal. Besides, humility had always seemed to him (A) a specious thing, invented for the comfort of others; you(X) were praised for humility by people because you(X) did not make them $(\mathbf{A})$ feel any more lacking than they $(\mathbf{A})$ already $\operatorname{did}$. $\operatorname{It}(\mathbf{C})$ was honesty that he $(\mathbf{A})$ valued; he $(\mathbf{A})$ had always wished himself (A) to be truly honest, and always feared that he (A) was not.

In the car on the way home from Chief's party, Kosi said, "Darling, you (A) must be hungry. You (A) ate only that $(\mathbf{X})$ spring roll?"

"And suya."

"You (A) need to eat. Thank God I (A) asked Marie to cook," she (A) said, and added, giggling,

"Me (A), I(A) should have respected myself(A) and left those $(\mathbf{X})$ snails alone! I (A) think I (A) ate up to ten. They (A) were so nice and peppery."

Obinze laughed, vaguely bored, but happy that she (A) was happy.

Marie was slight, and Obinze was not sure whether she (A) was timid or whether her (A) halting English made her (A) seem so. She (A) had been with them (A) only a month. The last house girl, brought by a relative of Gabriel's, was thickset and had arrived clutching a duffel bag. He (A) was not there (L) when Kosi looked through it (A) she did that routinely with all domestic help because she (A) wanted to know what was being brought into her(A) home - but he(A) came out when he(A) heard Kosi shouting, in that impatient, shrill manner she(A) put on with domestic help to command authority, to ward off disrespect. The girl's bag was on the floor, open, clothing fluffing out. Kosi stood beside it (A), holding up, at the tips of her (A) fingers, a packet of condoms.

"What is this (A) for? Eh? You (A) came to my (A) house to be a prostitute?"

The girl looked down at first, silent, then she (A) looked Kosi in the face and said quietly,

"In my (A) last job, my (A) madam's husband was always forcing me (A)."

Kosi's eyes bulged. She (A) moved forward for a moment, as though to attack the girl in some way, and then stopped.

"Please carry your (A) bag and go now-now (L)," she (A) said.

The girl shifted, looking a little surprised, and then she (A) picked up her (A) bag and turned to the door. After she (A) left, Kosi said, "Can you(C) believe the nonsense, darling? She (A) came here (L) with condoms and she (A) actually opened her (A) mouth to say that (A) rubbish. Can you (A) believe it (A)?"

"Her (A) former employer raped her (A) so she (A) decided to protect herself (A) this time (L)," Obinze said.

Kosi stared at him (A). "You (A) feel sorry for her (A). You (A) don't know these(X) house girls. How can you (A) feel sorry for her (A)?"

He (A) wanted to ask, how can you (A) not? But the tentative fear in her (A) eyes silenced him (A). Her (A) insecurity, so great and so ordinary, silenced him (A). She (A) was worried about a house girl whom it(C) would never even occur to him (A) to seduce. Lagos could do this(A) to a woman married to a young and wealthy man; he(A) knew how easy it(C) was to slip into paranoia about house girls, about secretaries, about Lagos Girls, those $(\mathbf{C})$ sophisticated monsters of glamour who swallowed husbands whole, slithering them(A) down their(A)jeweled throats. Still, he (A) wished Kosi feared less, conformed less.

Some years ago, he(A) had told her(A) about an attractive banker who had come to his(A)office to talk to him(A) about opening an account, a young woman wearing a fitted shirt with an extra button undone, trying to hide the desperation in her(A) eyes. "Darling, your (A) secretary should not let any of these(X) bank marketing girls come into your (A) office!" Kosi had said, as though she (A) seemed no longer to see him (A), Obinze, and instead saw blurred figures, classic types: a wealthy man, a female banker who had been given a target deposit amount, an easy exchange. Kosi expected him (A) to cheat, and her (A) concern was to minimize the possibilities he (A) might 
have. "Kosi, nothing can happen unless I (A) want it (A) to. I (A) will never want it (A) to," he (A) had said, in what was both a reassurance and a rebuke

She (A) had, in the years since they (A) got married, grown an intemperate dislike of single women and an intemperate love of God. Before they (A) got married, she (A) went to service once a week at the Anglican church on the Marina, a Sunday tick-the-box routine that she (A) did because she (A) had been brought up that way, but after their (A) wedding, she (A) switched to the House of David because, as she (A) told him (A), it (A) was a Bible-believing church. Later, when he (A) found out that the House of David had a special prayer service for Keeping Your Husband, he (A) had felt unsettled. Just as he (A) had when he (A) once asked why her (A) best friend from university, Elohor, hardly visited them (A), and Kosi said, "She (A)'s still single," as though that (A) was a self-evident reason.

Marie knocked on his (A) study door and came in with a tray of rice and fried plantains. He (A) ate slowly. He (A) put in a Fela CD and then started to write the e-mail on his (A) computer; his (A) BlackBerry keyboard would cramp his (A) fingers and his (A) mind. He (A) had introduced Ifemelu to Fela at university. She(A) had, before then(L), thought of Fela as the mad weed-smoker who wore underwear at his(A) concerts, but she(A) had come to love the Afrobeat sound and they(A)would lie on his(A) mattress in Nsukka and listen to it(A) and then she(A) would leap up and make swift, vulgar movements with her(A) hips when the run-run-run chorus came on. He (A) wondered if she (A) remembered that (A). $\mathrm{He}(\mathrm{A})$ wondered if she(A) remembered how his(A) cousin had sent mix tapes from abroad, and how he(A) made copies for her(A) at the famous electronics shop in the market where music blared all day long, ringing in your ears even after you(X)had left. He (A) had wanted her (A) to have the music he (A) had. She (A) had never really been interested in Biggie and Warren G and Dr. Dre and Snoop Dogg but Fela was different. On Fela, they (A) had agreed.

$\mathrm{He}(\mathbf{A})$ wrote and rewrote the e-mail, not mentioning his(A) wife or using the first person plural, trying for a balance between earnest and funny. He (A) did not want to alienate her (A). He (A) wanted to make sure she (A) would reply this time (L). He (A) clicked Send and then minutes later checked to see if she (A) had replied. He (A) was tired. It(A) was not a physical fatigue - he(A)went to the gym regularly and felt better than he(A) had in yearsbut a draining lassitude that(A) numbed the margins of his(A) mind. He(A) got up and went out to the verandah; the sudden hot air, the roar of his(A) neighbor's generator, the smell of diesel exhaust fumes brought a lightness to his(A) head. Frantic winged insects flitted around the electric bulb. He (A) felt, looking out at the muggy darkness farther away, as if he (A) could float, and all he (A) needed to do was to let himself (A) go.

\section{Excerpt $\mathbf{N}^{\circ} 2$}

Obinze checked his (A) BlackBerry often, too often, even when he (A) got up at night to go to the toilet, and although he (A) mocked himself (A), he (A) could not stop checking. Four days, four whole days, passed before she (A) replied. This (A) dampened him (A). She (A) was never coy, and she (A) would have ordinarily replied much sooner. She (A) might be busy, he (A) told himself (A), although he (A) knew very well how convenient and unconvincing a reason "busy" was. Or she (A) might have changed and become the kind of woman who waited four whole days so that she (A) would not seem too eager, a thought that (A) dampened him (A) even more. Her (A) e-mail was warm, but too short, telling him (A) she (A) was excited and nervous about leaving her (A) life and moving back home, but there were no specifics. When was she (A) moving back exactly? And what was it(X) that $(\mathbf{X})$ was so difficult to leave behind? He (A)Googled the black American again, hoping perhaps to find a blog post about a breakup, but the blog only had links to academic papers. One of them(A) was on early hip-hop music as political activism-how American, to study hip-hop as a viable subject-and he(A) read it(A) hoping it(A)would be silly, but it(A) was interesting enough for him(A) to read all the way to the end and this(A) soured his(A)stomach. The black American had become, absurdly, a rival. He (A) tried Facebook. Kosi was active on Facebook, she(A) put up photos and kept in touch with people, but he(A) had deleted his(A) account a while ago. He (A) had at first been excited by Facebook, ghosts of old friends suddenly morphing to life with wives and husbands and children, and photos trailed by comments. But he(A) began to be appalled by the air of unreality, the careful manipulation of images to create a parallel life, pictures that people had taken with Facebook in mind, placing in the background the things of which they(A) were proud. Now $(\mathbf{L})$, he (A) reactivated his $(\mathbf{A})$ account to search for Ifemelu, but she (A) did not have a Facebook profile. Perhaps she (A) was as unenchanted with Facebook as he (A) was. This (A) pleased him (A) vaguely, another example of how similar they (A) were. Her(A) black American was on Facebook, but his(A) profile was visible only to his(A) friends, and for a crazed moment, Obinze considered sending $\operatorname{him}(\mathbf{A})$ a friend request, just to see if he(A) had posted pictures of Ifemelu. $\mathrm{He}(\mathbf{A})$ wanted to wait a few days before replying to her(A) but he(A) found himself(A) that(A) night in his(A) study writing her(A) a long e-mail about the death of his(A) mother. I (A) never thought that she (A) would die until she (A) died. Does this (A) make sense? He (A) had discovered that grief did not dim with time; it (A) was instead a volatile state of 
being. Sometimes the pain was as abrupt as it(A) was on the day her(A) house help called him(A) sobbing to say she(A) was lying unbreathing on her(A) bed; other times, he(A) forgot that she(A) had died and would make cursory plans about flying to the east $(\mathbf{H})$ to see her(A). She (A) had looked askance at his (A) new wealth, as though she (A) did not understand a world in which a person could make so much so easily. After he(A) bought her(A)a new car as a surprise, $\operatorname{she}(\mathbf{A})$ told $\operatorname{him}(\mathbf{A}) \operatorname{her}(\mathbf{A})$ old car was perfectly fine, the Peugeot 505 she(A)had been driving since he(A) was in secondary school. $\operatorname{He}(\mathbf{A})$ had the car delivered to her(A)house, a small Honda that she(A) would not think too ostentatious, but each time he(A) visited, he(A) saw it(A) parked in the garage, coated in a translucent haze of dust. He (A) remembered very clearly his (A) last conversation with her (A) over the phone, three days before she (A) died, her (A) growing despondence with her (A) job and with life on the campus.

"Nobody publishes in international journals," she (A) had said. "Nobody goes to conferences. It (A)'s like a shallow muddy pond that we (A) are all wallowing in."

He (A) wrote this (A) in his (A) e-mail to Ifemelu, how his (A) mother's sadness with her (A) job had also made him (A) sad. He (A) was careful not to be too heavy-handed, writing about how the church in his hometown had made him (A) pay many dues before her (A) funeral, and how the caterers had stolen meat at the burial, wrapping chunks of beef in fresh banana leaves and throwing them (A) across the compound wall to their (A) accomplices, and how his (A) relatives had become preoccupied with the stolen meat. Voices were raised, accusations flung back and forth, and an aunt had said, "Those (A) caterers must return every last bit of the stolen goods!" Stolen goods. His (A) mother would have been amused about meat being a stolen good, and even by her (A) funeral ending up a brawl about stolen meat. Why, he (A) wrote to Ifemelu, do our(X) funerals become so quickly about other things that (A) are not about the person who died? Why do the villagers wait for a death before they(A) proceed to avenge past wrongs, those(A) real and those imagined, and why do they(A) dig deep to the bone in their(A) bid to get their(A) pound of flesh?

Ifemelu's reply came an hour later, a rush of heartbroken words. I (A) am crying as I (A) write this(C). Do you (A) know how often I (A) wished that she (A) was my mother? She(A) was the only adult—except for Aunty Uju - who treated me(A) like a person with an opinion that(A) mattered. You (A) were so fortunate to be raised by her (A). She (A) was everything I (A) wanted to be. I (A) am so sorry, Ceiling. I (A) can imagine how ripped apart you (A) must have felt and still sometimes feel. I (A) am in Massachusetts with Aunty Uju and Dike and I (A) am going through something right now (L) that (A) gives me (A) a sense of that (A) kind of pain, but only a small sense. Please give me (A) a number so I(A) can call—if it (A)'s okay.

Her (A) e-mail made him (A) happy. Seeing his (A) mother through her (A) eyes made him (A) happy. And it (A) emboldened him (A). He (A) wondered what pain she (A) was referring to and hoped that it (A) was the breakup with the black American, although he (A) did not want the relationship to have mattered so much to her (A) that the breakup would throw her (A) into a kind of mourning. He (A) tried to imagine how changed she (A) would be now (L), how Americanized, especially after being in a relationship with an American. There was a manic optimism that he(A) noticed in many of the people who had moved back from America in the past few years, a head-bobbing, ever-smiling, over-enthusiastic kind of manic optimism that bored him(A), because it(A) was like a cartoon, without texture or depth. He (A) hoped she (A) had not become like that (A). He (A) could not imagine that she (A) would have. She (A) had asked for his (A) number. She (A) could not feel so strongly about his (A) mother if she (A) did not still have feelings for him (A). So he(A) wrote her(A) again, giving her(A) all of his(A) phone numbers, his(A) three cell phones, his(A) office phone, and his(A) home landline. He (A) ended his (A) email with these(C) words: It(C)'s strange how I (A) have felt, with every major event that (A) has occurred in my (A) life, that you (A) were the only person who would understand. He (A) felt giddy, but after he (A) clicked Send, regrets assailed him (A). It (A) had been too much too soon. He (A) should not have written something so heavy. He (A) checked his (A) BlackBerry obsessively, day after day, and by the tenth day he (A) realized she (A) would not write back.

He (A) composed a few e-mails apologizing to her (A), but he (A) did not send them (A) because it (A) felt awkward apologizing for something he (A) could not name. He (A) never consciously decided to write her (A) the long, detailed e-mails that (A) followed. His (A) claim, that he (A) had missed her (A) at every major event in his (A) life, was grandiose, he (A) knew, but it (A) was not entirely false. Of course there were stretches of time when he(A) had not actively thought about her(A), when he(A) was submerged in his(A) early excitement with Kosi, in his(A) new child, in a new contract, but she(A) had never been absent. He (A) had held her (A) always clasped in the palm of his (A) mind. Even through her (A) silence, and his (A) confused bitterness.

He (A) began to write to her (A) about his (A) time in England, hoping she (A) would reply and then (L) later looking forward to the writing itself (A). He (A) had never told himself (A) his (A) own story, never allowed 
himself (A) to reflect on it (A), because he (A) was too disoriented by his (A) deportation and then by the suddenness of his (A) new life in Lagos (L). Writing her (A) also became a way of writing himself (A). He (A) had nothing to lose. Even if she (A) was reading his (A) e-mails with the black American and laughing at his (A) stupidity, he (A) did not mind.

FINALLY, she (A) replied.

Ceiling, sorry for the silence. Dike attempted suicide. I(A) didn't want to tell you(A) earlier (and I(A) don't know why). He(A)'s doing much better, but it(A) has been traumatic and it(A)'s affected me(A) more than I(A) thought it(A) would (you(A) know, "attempted" doesn't mean it(A) happened, but I (A)'ve spent days crying, thinking about what might have happened). I(A)'m sorry I(A) didn't call to give you(A) my(A) condolences about your(A) mother. I(A) had planned to, and appreciated your(A) giving me(A)your(A) phone number, but I(A) took Dike to his(A) psychiatrist appointment that(A) day and afterwards, I(A) just couldn't get myself(A) to do anything. I (A) felt as if I (A) had been felled by something. Aunty Uju tells me (A) I (A) have depression. You (A) know America has a way of turning everything into an illness that (A) needs medicine. I (A)'m not taking medicines, just spending a lot of time with Dike, watching a lot of terrible films with vampires and spaceships. I(A) have loved your(A) emails about England and they(A) have been so good for me(A), in so many ways, and I(A) cannot thank you(A) enough for writing them(A). I (A) hope I (A) will have a chance to fill you (A) in on my (A) own life-whenever that (A) is. I(A)'ve just finished a fellowship at Princeton and for years I(A) wrote an anonymous blog about race, which then(L) became how I(A) made my(A) living, and you(A) can read the archives here(L). I (A)'ve postponed my (A) return home (L). I (A)'ll be in touch. Take care and hope all is well with you (A) and your (A) family.

Dike had tried to kill himself (A). It (A) was impossible to comprehend. His (A) memory of Dike was of a toddler, a white puff of Pampers at his (A) waist, running around in the house in Dolphin Estate. Now (L) he (A) was a teenager who had tried to kill himself (A). Obinze's first thought was that he (A) wanted to go to Ifemelu, right away. He (A) wanted to buy a ticket and get on a plane to America and be with her (A), console her (A), help Dike, make everything right. Then he (A) laughed at his (A) own absurdity.

"Sorry, omalicha," he (A) said.

"No work thoughts for now (L)."

"Okay, sorry. What were you (A) saying?"

They(A) were in the car, on their(A) way to a nursery-primary school in Ikoyi, visiting during the open day as guests of Jonathan and Isioma, Kosi's friends from church, whose son went there(L). Kosi had arranged it (A) all, their (A) second school visit, to help them (A) decide where Buchi would go.

Obinze had spent time with them (A) only once, when Kosi invited them (A) to dinner. He(A)thought Isioma interesting; the few things she(A) allowed herself(A) to say were thoughtful, but she(A) often remained silent, shrinking herself(A), pretending not to be as intelligent as she(A) was, to salve Jonathan's ego, while Jonathan, a bank CEO whose photos were always in the newspapers, dominated the evening with long-winded stories about his(A)dealings with estate agents in Switzerland, the Nigerian governors he(A) had advised, and the various companies he(A) had saved from collapse.

He (A) introduced Obinze and Kosi to the school headmistress, a small round Englishwoman, saying, "Obinze and Kosi are our $(\mathbf{X})$ very close friends. I (A) think their (A) daughter might be joining us(X) next year (L)."

"Many high-level expatriates bring their (A) children here (L)," the headmistress said, her (A) tone pride-tinged, and Obinze wondered if this (A) was something she (A) said routinely. She (A) had probably said it (A) often enough to know how well it (A) worked, how much it (A) impressed Nigerians.

Isioma was asking why their (A) son was not yet doing much of mathematics and English.

"Our( $\mathbf{X})$ approach is more conceptual. $\mathrm{We}(\mathbf{X})$ like the children to explore their (A) environment during the first year," the headmistress said.

"But it (A) should not be mutually exclusive. They (A) can also start to learn some maths and English," Isioma said. Then, with an amusement that (A) did not try to shield its (A) underlying seriousness, she (A) added, "My (A) niece goes to a school on the mainland (L) and at age six she (A) could spell 'onomatopoeia'!"

The headmistress smiled tightly; she (A) did not, her (A) smile said, think it(C) worthwhile to address the processes of lesser schools. Later, they (A) sat in a large hall and watched the children's production of a Christmas play, about a Nigerian family who find an orphan on their (A) doorstep on Christmas Day. Halfway through the play, a teacher turned on a fan that (A) blew small bits of white cotton wool around the stage. Snow. $\operatorname{It}(\mathbf{C})$ was snowing in the play. 
"Why do they $(\mathbf{X})$ have snow falling? Are they $(\mathbf{X})$ teaching children that a Christmas is not a real Christmas unless snow falls like it (A) does abroad?" Isioma said.

Jonathan said, "Ahn-ahn, what is wrong with that (A)? It (A)'s just a play!"

"It (A)'s just a play, but I(C) also see what Isioma is saying," Kosi said, and then turned to Obinze."Darling?"

Obinze said, "The little girl that (A) played the angel was very good."In the car, Kosi said, "Your (A) mind is not here $(\mathbf{L}) . "$

HE (A) READ all the archives of Raceteenth or Various Observations about American Blacks (Those (A) Formerly Known as Negroes) by a Non-American Black. The blog posts astonished him(A), they(A) seemed so American and so alien, the irreverent voice with its(A) slanginess, its(A)mix of high and low language, and he(A) could not imagine her(A) writing them(A). He (A) cringed reading her (A) references to her (A) boyfriends- The Hot White Ex, Professor Hunk. He(A) read "Just This(X) Evening" a few times, because it(A) was the most personal post she(A) had written about the black American, and he(A) searched for clues and subtleties, about what kind of man he(A) was, what kind of relationship they(A) had.

So in NYC (L), Professor Hunk was stopped by the police. They (A) thought he (A) had drugs. American Blacks and American Whites use drugs at the same rate (look this (A) up), but say the word "drugs" and see what image comes to everyone's mind. Professor Hunk is upset. He (A) says he (A)'s an Ivy League professor and he (A) knows the deal, and he (A) wonders what it(C) would feel like if he (A) were some poor kid from the inner city (L). I (A) feel bad for my (A) baby. When we(X) first met, he (A) told me (A) how he (A) wanted to get straight As in high school because of a white teacher who told him (A) to "focus on getting a basketball scholarship, black people are physically inclined and white people are intellectually inclined, it (A)'s not good or bad, just different" (and this (A) teacher went to Columbia, just sayin'). So he (A) spent four years proving her (A) wrong. I (A) couldn't identify with this $(\mathbf{C})$ : wanting to do well to prove a point. But I (A) felt bad then $(\mathbf{L})$ too. So off to make him (A) some tea. And administer some TLC.

Because he (A) had last known her (A) when she (A) knew little of the things she (A) blogged about, he (A) felt a sense of loss, as though she (A) had become a person he (A) would no longer recognize.

\section{Copyrights}

Copyright for this article is retained by the author(s), with first publication rights granted to the journal.

This is an open-access article distributed under the terms and conditions of the Creative Commons Attribution license (http://creativecommons.org/licenses/by/4.0/). 